\title{
Electromagnetic Engine with an Objective of Lowering Pollution
}

\author{
Akshay Mannur ${ }^{1}$, Rohan Patil ${ }^{2}$, Shubham Padalkar ${ }^{3}$, Koustubh Prem $^{4}$ \\ Department of Mechanical Engineering, Jain College of Engineering, Belagavi, Karnataka, India ${ }^{1,3,4}$ \\ Department of Electronics and Communication Engg, Jain College of Engineering, Belagavi, Karnataka, India ${ }^{2}$
}

\begin{abstract}
The age of power transmission evolving from steam engines to internal combustion engines and then to electric power. This electric power can be further simplified and used in the form of an electromagnetic engine. Magnetism is the basic principle of working for an electromagnetic engine. The general property of magnet i.e. attraction and repulsion forces is converted into mechanical work. We plan to change the conventional engines with a new class of engine which work on principle of magnetism electromagnetism and AC magnetic fields. We can say that no such engines exist which can produce no emission and does not take time for starting(charging of battery in electric engines) and the concept of using ac magnetic fields is new for these engines making them much more efficient.
\end{abstract}

Index Terms: A.C Magnetic field, Solenoid.

\section{INTRODUCTION}

With the diminishing fossil fuel resources and unabated increase in energy costs and environmental concerns, engines using alternate energy sources such as bio-fuel, solar power, wind power, electric power, stored power, etc are being developed around the world. The solar power is not efficient. Added to all, the initial capital and subsequent maintenance costs for machines that use alternate energy sources are very high. Hence, in the absence of a viable alternative, until now, switching to new technology by changing from traditional Internal Combustion engines has been a challenge. However, such engines still have many limitations. So the main problem of this era is the increase in pollution and no better option to reduce this pollution and the fleet average $\mathrm{CO}_{2}$ emission of India has been predicted to be $113 \mathrm{~g} / \mathrm{km}$ similarly for china and United States it has been estimated $117 \mathrm{~g} / \mathrm{km}$ and $121 \mathrm{~g} / \mathrm{km}$ respectively which still are high. The engine consists, the cylinder head which is an electromagnet and a permanent magnet is attached to the piston head. When the electromagnet is charged, it attracts or repels the magnet, thus pushing then piston downwards or upwards thereby rotating the crankshaft. This is how power is generated in the electromagnetic engine. It utilizes only repulsive force that allows the field to dissipate completely, and have no restrictive effects on the rising piston. The electromagnetic engine should ideally perform exactly the same as the internal combustion engine. The power of the engine is controlled by the strength of the field and the strength of the field is controlled by the amount of windings and the current that is being passed through it. If the current is increased the power generated by the engine also increases accordingly. The current that is used to charge the electromagnet is taken from the AC current which is produced by conversion of rotational to electrical energy. The main advantages of electromagnetic engine are that it is pollution free. Also it is easy to design an electromagnetic engine because there are no complicated parts. Since the engine doesn't have combustion, valves, fuel pump, fuel lines, air and fuel filters and inlet and exhaust manifolds etc. can be eliminated from the engine. The main challenge faced in designing an electromagnetic engine is that it has to be as efficient as an internal combustion engine.

\section{THE CONCEPT INVOLVED}

The working of the electromagnetic engine is based on the principle of magnetism. A magnet has two poles a north pole and a south pole. Magnetism is a class of physical phenomenon that includes forces exerted by magnets on other magnets. By principle of magnetism, when like poles of a magnet is brought together they repel away from each other. When unlike poles are brought near each other they attract. This is same for the case of an electromagnet and a permanent magnet too. So the idea is to modify the piston head and cylinder head into magnets so that force can be generated between them.

\section{WORKING}

The working of the electromagnetic engine is based on attraction \& repulsive force of the magnet. The engine greatly resembles the working of a two-stroke engine. 
The main obstacle to overcome was to start the engine directly with alternating current therefore an auxiliary power supply has been provided for starting of the engine and the power supply accumulates energy from the batteries provided this current flows directly through the electromagnets which in turn generates the magnetic field.

Let us consider that the piston is at bottom dead center, and then the piston aligned to the crank shaft is at the top dead center, now the repulsive force between the piston head and the cylinder head takes place and repulses the piston towards the bottom dead center due to the repulsive force created. Due to the rotation of the crank shaft, alternating current is generated as the crank shaft is connected to the AC dynamo. This produced current is then supplied as input to the solenoid with iron core; hence solenoid acts as an electromagnet. This in turn behaves as a mechanism of an internal combustion engine and results in the movement of the vehicle.

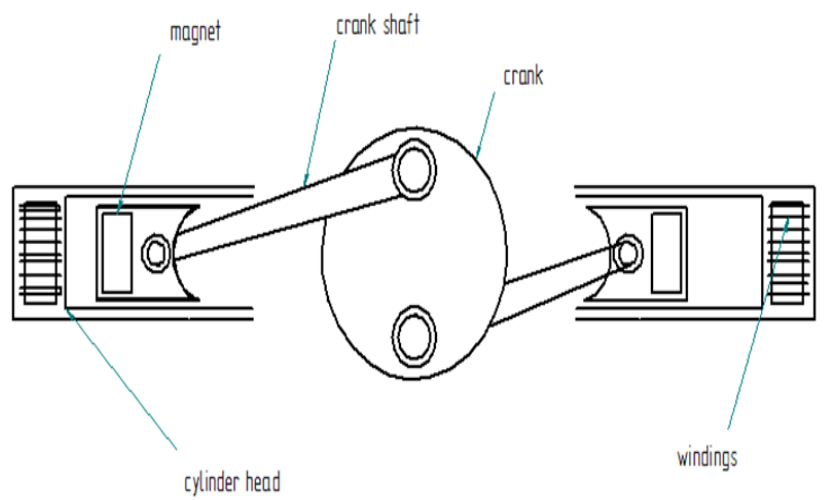

Fig 1: The sectional view of the engine

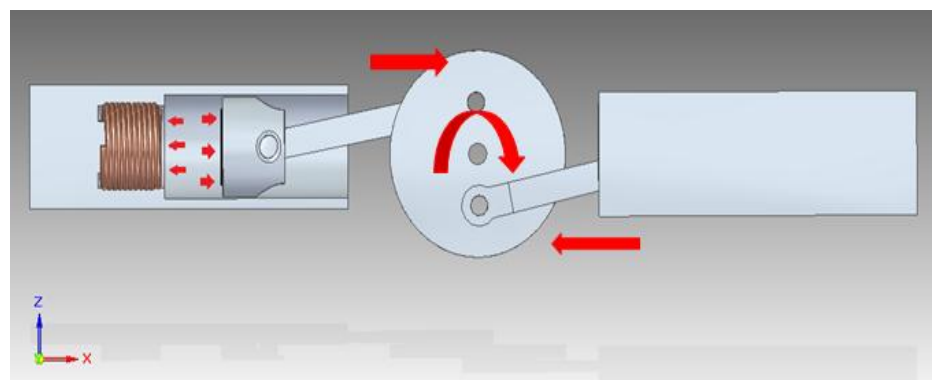

Fig 2.1: the working mechanism

When the piston is pushed away by the solenoid with an iron core the repulsive forces between them cause a couple at the crankshaft making it rotate and the cycle continues as it reaches to bottom dead centre (BDC).

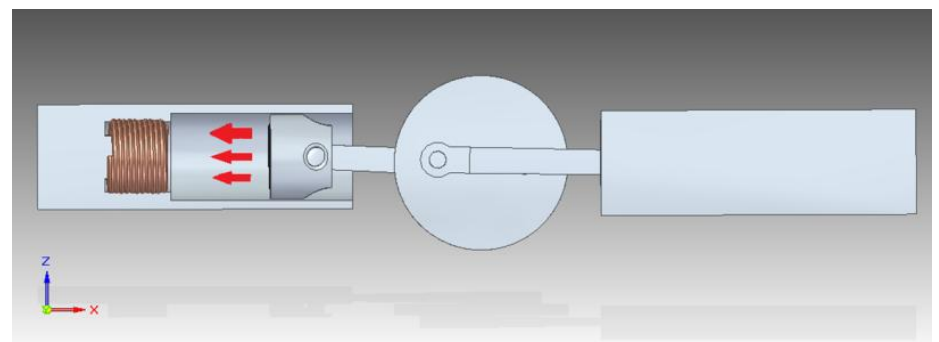

Fig 2.2 The working mechanism (compression view)

Here the piston reaches the bottom dead center (BDC). The polarity of the elecromagnet reverses resulting in attracting of cylinder head and piston. And this cycle continues.

\section{MAGNETIC PROPERTIES}

1. Remanence $\left(\mathbf{B}_{\mathbf{r}}\right)$ : This measures the strength of the magnetic field

2. Coercivity $\left(\mathbf{H}_{\mathbf{c}}\right)$ : The material's resistance to become demagnetize.

3. Energy product $\left(\mathbf{B H}_{\max }\right)$ : The density of magnetic energy.

4. Curie Temperature $\left(\mathbf{T}_{\mathbf{c}}\right)$ : The temperature at which material loses its magnetism. 
Here for $\mathrm{Nd}_{2} \mathrm{Fe}_{14} \mathrm{~B}$ (sintered)

$\mathrm{B}_{\mathrm{r}}=1.0-1.4 \mathrm{~T}$

$\mathrm{H}_{\mathrm{ci}}=750-2000 \mathrm{kA} / \mathrm{m}$

$\mathrm{BH}_{\max }=200-440 \mathrm{~kJ} / \mathrm{m}^{3}$

$\mathrm{T}_{\mathrm{c}}=310-400^{\circ} \mathrm{C}$

has overall the best property for a strong suitable and durable permanent magnet and having the strongest grade of N52 magnets.

Since there is no combustion or any other type of high temperature activity we can choose $\mathrm{Nd}_{2} \mathrm{Fe}_{14} \mathrm{~B}$ (sintered) as a suitable magnet for the overall operation of the engine.

\section{Solenoids}

Solenoids are long straight coil of wire that can be used to generate uniform magnetic field similar to that of a bar / disc / cylindrical magnets. And when a iron core is placed inside the solenoid coil the strength of magnetic field increases exponentially and hence a electromagnet is prepared with just a wounded wire and a piece of iron placed inside the coil.

Electromagnets are usually in the form of iron core solenoids. The ferromagnetic property of the iron core causes the internal magnetic domains of the iron to line up with the smaller driving magnetic produced by the current in the solenoid.

The solenoid field relationship is $\mathrm{B}=\mathrm{k} \mu_{0} \mathrm{nI}$ where $\mu=\mathrm{k} \mu_{0}$ here $\mathrm{k}$ is relative permeability .

The force produced by the solenoid with iron core can be calculated by the following equation:-

$\mathrm{F}=(\mathrm{N} * \mathrm{I})^{2} \mu_{0} \mathrm{~A} /\left(2 \mathrm{~g}^{2}\right)$

\section{CALCULATIONS INVOLVED}

$\mathrm{F}=(\mathrm{N} * \mathrm{I})^{2} \mu_{0} \mathrm{~A} /\left(2 \mathrm{~g}^{2}\right)$

Here, $\mathrm{N}=$ number of the winding's $/$ turns (1000 turns)

$$
\mathrm{I}=\text { current provided to the coil }(6 \mathrm{~A})
$$

$\mu_{0}=4 \pi \times 10^{-7}$

$\mathrm{A}=$ the area in length units squared $\left(1.75 \mathrm{~cm}^{2}\right)$

$\mathrm{G}=$ the gap between the core and turns $\left(.2 \mathrm{~cm}^{2}\right)$

$\mathrm{F}=(1000 * 6)^{2} * 4 \pi \times 10^{-7} * 1.75 /\left(2 * .2^{2}\right)$

$\mathrm{F}=989.6017 \mathrm{~N}$

\section{Magnetic force field equation:}

$\mathrm{F}=\mathrm{B}^{2} \times \mathrm{A} /(2 \mu)$

Here, $\mathrm{B}=$ magnetic field

$\mathrm{A}=$ area of the cylindrical magnets

$\mu=4 \pi \times 10^{-7}$

$\mathrm{B}=\mathrm{K}_{\mathrm{m}} \mu_{0} \mathrm{H}$

Here $\mathrm{H}=2000(\mathrm{kA} / \mathrm{m})$

$\mathrm{K}_{\mathrm{m}}=1.05$

$\mathrm{B}=1.05 * 2000 * 1000 * 4 \pi \times 10^{-7}$

$=2.6389(\mathrm{~T})$

Force field equation

$\mathrm{F}=\mathrm{B}^{2} \times \mathrm{A} /(2 \mu)$

$\mathrm{F}=2.6389^{2} * \pi^{*} .009^{2} /\left(2 * 4 \pi \times 10^{-7}\right)$

$\mathrm{F}=705.084 \mathrm{~N}$

Total Repulsive Force of the piston is $=705.084+989.6017=1694.6857 \mathrm{~N}$

\section{* ADVANTAgeS}

- No fuel is used in these engines so no refuelling, hence no pollution.

- No batteries for running these engine, just used for starting of engine so no wastage of time in charging of vehicle.

- Affordability of these engines will be better than the current market engine.

- Running cost of these engines compared to petrol or electric vehicles is less.

- As for the maintenance point of view timely evaluation of piston and cylinder has to be done for proper working.

- In this engine we reduce the complications by removing combustion, valves, fuel pumps, air and fuel filter and inlet and exhaust manifolds. 


\section{* LIMITATIONS}

- Regular checkup of the engine is required

- The engine can't perform for very long journey because of loss of magnetic power due to heat in magnets.

- Extra storage compartment for coolant is required.

- Low grade magnets cannot be used. Magnets used should be of the specific properties.

\section{CONCLUSION}

As per the focus of the project we have provided an innovative solution for reducing the usage of fossil fuels and reduce pollution. As well as providing the same level of efficiency as that of conventional engines. So we can conclude that with a little higher cost of initial investment we can achieve the same output as we have with the regular engines. And even saving the cost of fuel hence proving it to be economical and viable solution.

\section{FUTURE SCOPE}

\section{Future scope}

- To implement this engine to trains; can save fuel and less pollution

- To eradicate conventional engines

- These engines can be used as generators at power cut-offs

- The engines can be implemented for local transport systems

- No fuel, low noise, no pollution

\section{REFERENCES}

[1] Introduction to Electrodynamics 2015 By David J. Griffiths

[2] S.S Ratan Tata McGraw -hill Education; Theory of machines

[3] Internal combustion engines by V.Ganesan

[4] Internal combustion engine fundamentals (Book by John B. Heywood).

\section{BIOGRAPHIES}

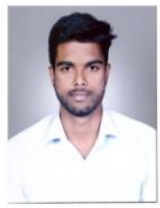

Mr Akshay Mannur, Department of Mechanical Engineering, Jain College of Engineering, Belagavi

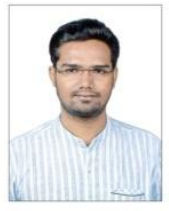

Mr Rohan Patil, Department of Mechanical Engineering, Jain College of Engineering, Belagavi

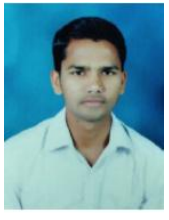

Shubham Padalkar, Department of Mechanical Engineering, Jain College of Engineering, Belagavi

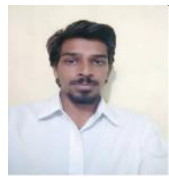

Koustubh Prem, Department of Mechanical Engineering, Jain College of Engineering, Belagavi 